\title{
ESTUDO ANTROPOMÉTRICO-NUTRICIONAL DE PRÉ-ESCOLARES DE AREAS DE BAIXA RENDA DO ESTADO DE SÃO PAULO, BRASIL
}

\author{
Carlos Augusto Monteiro* \\ Isildinha Marques dos Reis* \\ Maria Helena D'Aquino Benicio* \\ Yaro Ribeiro Gandra*
}

MONTEIRO, C.A. et al. Estudo antropométrico-nutricional de pré-escolares de áreas de baixa renda do Estado de São Paulo, Brasil, Rev. Saúde públ., S. Paulo, 18:1-18, 1984.

RESUMO: Com o objetivo de avaliar o estado nutricional na idade pré-escolar em áreas de baixa renda do Estado de São Paulo, 1.359 crianças de dois a seis anos de idade foram submetidas a exame antropométrico que incluiu peso e altura e medidas das áreas "muscular" e "adiposa" da seção transversal do braço esquerdo. A análise das medidas observadas foi feita por comparação a medidas que foram simultaneamente tomadas em população de pré-escolares de alto nível sócio-econômico do município de São Paulo. Foram comparadas médias segundo faixa etária e, a seguir, por meio de análises de regressão em função da idade, foram comparadas as velocidades de expansão das várias medidas. As análises efetuadas indicam que, ao chegar ao final da idade pré-escolar, as crianças das áreas de baixa renda apresentam pronunciado retardo no seu crescimento (aproximadamente $5 \mathrm{~cm}$ de altura e $5 \mathrm{~kg}$ de peso). A seção transversal do braço daquelas crianças estaria, no mesmo momento, diminuída tanto em tecido muscular quanto em tecido adiposo (em torno de $2 \mathrm{~cm}^{2}$ e $4 \mathrm{~cm}^{2}$, respectivamente). As mesmas análises indicam cronologias diferentes para os vários déficits constatados ao final da idade pré-escolar. Os déficits de altura e de "área muscular" do braço ocorreriam predominantemente antes dos dois anos de idade enquanto os déficits de peso e de "área adiposa" do braço aconteceriam predominantemente já na idade pré-escolar. Como implicaçôes dos achados obtidos, surgem indicações de que, antes dos dois anos, a interação agente-hospedeiro; responsável pelo aparecimento da desnutrição, determine prejuízos sobretudo à síntese de proteínas. No período pré-escolar, aquela interação detèrminaria prejuízos sobretudo à sintese das reservas calóricas. Modificações a nível do agente e/ou a nível do hospedeiro poderiam ser responsáveis pelas diferenças observadas nos dois períodos. Para a compreensão das mesmas, fatores como a adequação calórica e protéica das dietas, a incidencia e severidade das doenças infecciosas e os mecanismos adaptativos do organismo deveriam ser investigados. De qualquer forma, a diversidade do comprometimento do estado nutricional nos dois periodos deveria ser levada em conta na formulação dos programas de nutrição dirigidos às várias idades.

UNITERMOS: Antropometrica - Pré-escolares - Estado nutricional. Desnutrição.

* Do Departamento de Nutrição da Faculdade de Saúde Pública da Universidade de São Paulo - Ar. Dr. Arnaldo, 715 - 01255 - São Paulo, SP - Brasil. 
MONTEIRo, C.A. et al. Estudo antropométrico-nutricional de pré-escolares de áreas de baixa renda do Estado de São Paulo, Brasil. Rev. Saúde públ., S. Paulo, 18:1-18, 1984.

\section{1 - INTRODUÇÃO}

Utilizando diferentes técnicas e enfocando diferentes problemas, a avaliação do estado nutricional tem-se constituído, ao longo do tempo, em importante peça do acervo de instrumentos disponíveis para a apreciação das condições de saúde de indivíduos e de populações.

Atualmente se admite que a avaliação do estado nutricional feita por meio do acompanhamento da velocidade de crescimento seja o método de excelência para a averiguação das condições infantis de saúde 27 . Por outro lado, as médias de peso e altura alcançadas pelo conjunto das crianças de uma determinada região indicariam fidedignamente as condiçōes gerais de saúde e nutrição ali vigentes ${ }^{3}$. Demonstrações destes reconhecimentos podem ser vistas na incorporação da vigilância do crescimento aos programas de controle da saúde infantil 21,22 e na utilização de inquéritos antropométricos para monítorização do desenvolvimento social de paises ${ }^{16}$.

Mais recentemente, outros indicadores antropométricos do estado nutricional vêm sendo propostos, seja como substitutos das medidas de peso e altura, seja como complementos das mesmas. Nesta última qualidade, são propostas as medidas das áreas "muscular" e "adiposa" do braço 11,18. Sua obtenção se dá a partir das medidas do perímetro do braço e da dobra cutânea tricipital, ambas efetuadas exatamente na metade do braço. A partir daquelas medidas, são determinadas duas áreas concêntricas da seção transversal do braço: a área interna, constituída predominantemente de tecido muscular, denominada "área muscular do braço", e a área externa, constituída predominantemente de tecido adiposo, denominada "área adiposa do braço". A determinação das referidas áreas considera a seção do úmero na "área muscular" e assume formato cilíndrico para o braço e seu compartimento muscular, além de admitir distribuição uniforme para o tecido adiposo que envolve o braço. Apesar destas aproximaçōes, estudos radiográficos ${ }^{15}$, e mais recentemente estudos com tomografia computadorizada ${ }^{12}$, têm demonstrado alta correlação entre os valores calculados pela antropometria e os valores calculados por aquelas técnicas mais refinadas. A utilização das medidas das áreas "muscular" e "adiposa" do braço encontra papel sobretudo em permitir o acesso à investivação das reservas protéicas e calóricas do organismo, sendo 0 tecido muscular entendido como reserva de proteínas não só por representar o componente principal da massa magra do organismo ${ }^{15}$, como também pelas evidências que comprovam seu decréscimo na vigência de processo de desnutrição 25,30 , quando a massa muscular passa a fornecer aminoácidos para a neoglicogênese e a síntese de proteinas no fígado ${ }^{1}$.

No Brasil, a avaliação do estado nutricional por meio da antropometria vem sends crescentemente empregada. De modo geral, as amostras estudadas são de crianças menores de cinco anos e a avaliação é feita utilizando a adequação percentual do peso à idade, classificada segundo os critérios sugeridos por Gomez 8 . Os resultados das investigações têm acusado elevada prevalência de desnutrição e grandes disparidades regionais e sócio-econômicas 19 . Têm indicado, também, que, nas áreas urbanas, a renda familiar "per capita" se constitui em excelente indicador preditivo da desnutrição, sendo um salário mínimo "per capita" o limite superior de um estrato populacional particularmente sujeito a risco ${ }^{9,24}$.

A utilização do exame antropométrico do braço na avaliação do comprometimento diferenciado de tecidos não se vem fazendo de forma sistemática no Brasil e os estudos que têm incluído as medições do perímetro braquial e da dobra cutânea tricipital não têm chegado as cálculo e posterior análise do desempenho das denominadas áreas "muscular" e "adiposa" do braço. 
MONTEIRO, C.A. et al. Estudo antropométrico-nutricional de pré-escolares de áreas de baixa renda do Estado de São Paulo, Brasil. Rev. Saúde públ., S. Paulo, 18:1-18, 1984.

Entre 1977 e 1979, o Departamento de Nutrição da Faculdade de Saúde Pública esteve em várias áreas de baixa renda do Estado de São Paulo realizando inquéritos antropométricos na população de 2 a 6 anos de idade. Por meio destes inquéritos, foram obtidas precisas medidas de peso, altura, perimetro braquial e dobra cutânea tricipital de 1.359 pré-escolares.

A partir do referido material, pretende-se conhecer qual a situação do estado nutricional naquelas áreas de baixa renda. Mais especificamente pretende-se sabar quando ocorrem os possiveis agravos nutricionais, qual a sua intensidade e que comprometimentos antropométricos predominantes causam ao organismo.

$$
2 \text { - MATERIAL E Métodos }
$$

A população estudada compreende 1.359 crianças de 2 a 6 anos de idade *, residentes em áreas de atuação dos Centros de Educação e Alimentação do Pré-Escolar (CEAPEs) ${ }^{7}$, no Estado de São Paulo. Estas áreas estão situadas no interior do Estado, a oeste da Capital, nos Municípios de Campinas, Capivari, Indaiatuba, Sumaré, Leme e São Carlos. Dada a proposta dos CEAPEs como alternativas simplificadas para expansão da atenção pré-escolar a áreas carentes ?, as áreas abrangidas pelo estudo são constituídas pelos bairros mais pobres daqueles municipios. Em comum, estas áreas se caracterizam por se situarem no anel periférico que envolve a sede dos municípios, por não serem alcançadas pela infra-estrutura urbana que serve às sedes e por possuírem a maioria de suas familias vivendo com renda mensal abaixo de um salário mínimo "per capita"**.

Em função desta última característica, no presente estudo, estas áreas serão denomi- nadas "áreas de baixa renda". Assinale-se, a este respeito, que pesquisas realizadas no Estado ae Jao raulo ${ }^{y, 24}$ e em outros Estados prasileirus ${ }^{y}$ tem demonstrado que rendas mensais interiores a un salário-mınımo "per capıta" contıguram estrato sócio-econômıco partıcularmente vulnerável à desnutrição.

No estudo foram incluídos todos os pré-escolares que se matricularam nos CEAPEs daquelas áreas entre 1977 e 1979 (neste caso, as medidas foram obtidas sempre em data próxima à matrícula) e amostras dos pré-escolares residentes nas áreas, mas não matriculados no programa. Entre os pré-escolares matriculados e os apenas residentes não foram constatadas importantes diferenças, nem quanto à renda familiar, nem quanto ao estado nutricional. Em função disto, o conjunto dos pré-escolares examinados deve indicar a situação nutricional global que prevalece nas áreas.

Paralelamente ao estudo antropométrico nas áreas de baixa renda do Estado, idêntico estudo foi realizado no município de São Paulo em 247 pré-escolares procedentes de famílias de alto nível sócio-econômico. Estas crianças freqüentavam, em 1978, estabelecimento pré-escolar da Capital que, purr sua localização e custo financeiro, era apenas acessivel a familias de elevado poder aquisitivo. As medidas destes pré-escolares irão constituir o padrão antroponétrico de referência, contra o qual serão comparadas as medidas observadas nas áreas de baixa renda. A opção de se construir um pađrão próprio de referência se prendeu a necessidades ditadas pelos objetivos da pesquisa e pelos procedimentos estatísticos utilizados na análise dos dados.

Os dados foram coletados, de modo idêntico, nas duas populações e compreenderam

* Para evitar repetiçoes desnecessárias, doravante as crianças de 2 a 6 anos de idade serão denominadas simplesmente de "pré-escolares", e como "pré-escolar" entender-se-á o período etário que vai dos 2 aos 6 anos de idade.

* A partir de amostras de pré-escolares residentes nas referidas áreas, matriculados ou năc nos CEAPEs, verifico ${ }^{-s e}$ que 89 a $95 \%$ deles provinham de familias com rendimentos mensais inferiores a um salário-mínimo "per capita". 
MONTEIRO, C.A. et al. Estudo antropométrico-nutricional de pré-escolares de áreas de baixa renda do Estado de São Paulo, Brasil. Rev. Saúăe públ., S. Paulo, 18:1-18, 1984.

a verificação da data de nascimento para posterior cálculo de idade em meses do pré-escolar e a tomada de medidas de peso, altura, perimetro braquial e dobra cutânea tricipital. As técnicas e os equipamentos utilizados na antropometria acham-se detalhadámente descritos em publicação anterior 19 e obedeceram diretrizes recomendadas por Jelliffe ${ }^{14}$ em monogratia sobre avaliação do estado nutricional. Diversos procedimentos foram adotados visando a máxıma redução do erro na tomada das medidas, destacando-se a dupla medição de todos os pré-escolares (por diferentes antropometristas) e a repetıção de medidas em caso de diferenças superiores a $100 \mathrm{~g}$ para peso, superior a $5 \mathrm{~mm}$ para altura e perimetro braquial e superiores a $1 \mathrm{~mm}$ para dobra cutànea (no caso de diferenças menores, a média aritmética entre as medidas era o resultado adotado).

Os indicadores antropométricos utilizados no estudo foram, além do peso e da altura, a relação peso/altura expressa em $\mathrm{kg} / \mathrm{cm}$ e as áreas da seção transversal do braço expressas em mm $\mathrm{m}^{2}$. A área total da seção transversal do braço (T) foi calculada a partir da medida do perímetro braquial (P) em milímetros, através da fórmula: $T=\frac{\mathrm{P}^{2}}{4 \pi}$. A "área muscular" da seção transversal do braço $(M)$ foi calculada a partir das medidas do perimetro braquial (P) e da dobra cutânea (D), ambas em milímetros, segundo a fórmula: $M=\frac{(P-\pi . D)^{2}}{4 \pi} \cdot A$ "área adiposa" da mesma seção foi derivada por subtração a partir dos valores atribuidos à área total e à "área muscular".

A avaliação do estado nutricional dos pré-escolares das áreas de baixa renda, durante o periodo pré-escolar, se baseou nos valores alcançados, em determinadas idades, pelas suas medidas de peso, altura, relação peso/altura e áreas da seção transversal do braço. A açڤquação destes valores foi julgada sempre em função dos valores encontrados na população de pré- -escolares de alto nível sócio-econômico, cujas condições de nutrição foram consideradas ideais.

Tanto nas áreas de baixa renda quanto na população de alto nivel sócio-econômico, os pré-escolares foram considerados independentemente do sexo. Como as diferenças nas medidas dos dois sexos são ainda relativamente pequenas na idade pré-escolar e, principalmente, porque em ambas as populações a proporçăo de meninos e meninas esteve próxima de $50 \%$ em todas as idades, julgou-se desnecessária a subdivisão das análises segundo o sexo. Esta subdivisão teria o inconveniente de reduzir o poder discriminatório dos procedimentos analíticos utilizados. Quando, na discussão, houve necessidade de citar resultados referentes a outras populações de pré-escolares, estes resultados sempre se referiram à média aritmética dos resultados dos dois sexos.

As comparações efetuadas entre as medidas das duas populações foram inicialmente feitas por meio do cotejamento de médias em cada faixa anual de idade. A seguir, foram conduzidas, separadamente nas duas populações, análises de regressão das várias medidas em função da idade em meses. A partir destas análises, foram obtidas regressões cujos coeficientes indicaram a velocidade de crescimento de cada uma das medidas no periodo pré-escolar. Estas velocidades foram, então, comparadas nas duas populações.

A análise estatística das diferenças encontradas com relação a médias foi procedida por meio do teste $\mathbf{t}$ de Student para dados independentes ${ }^{26}$.

Para a análise estatistica das diferenças encontradas em termos de velocidade de crescimento, dois procedimentos sucessivos foram utilizados. O primeiro procedimento foi o exame do significado estatístico do coeficiente de regressão de cada população. No caso de ambos os coeficientes serem significativos, passava-se ao segundo procedimento: o exame do significado estatístico 
MONTEIRO, C.A. et al. Estīūo antropométrico-nutricional de pré-escolares dé áreas de baixa renda do Estado de São Paulo, Brasil. Rev. Saúde públ., S. Paulo, 18:1-18, 1984.

da diferença observada entre os dois coeficientes. Os testes utilizados nos dois procedimentos foram, respectivamente, 0 teste de um coeficiente de regressão 26 (apoiado na estatística F) e o teste da diferença entre dois coeficientes de regressão ${ }^{26}$ (apoiado na estatística $Z$ ).

A probalidade crítica adotada "a priori" para a falsa rejeição da hipótese nula (não diferença) foi de $5 \%$. A título descritivo, são fornecidas, em todos os testes, as probabilidades realmente associadas à falsa rejeição da hipótese nula (nivel descritivo do teste).

$$
3 \text { - RESULTADOS }
$$

\subsection{Avaliação a partir dos dados de peso e altura}

3.1.1. Médias de peso, altura e relação peso/altura nas diversas faixas etárias

Na Tabela 1 encontram-se as médias obtidas nas diversas faixas etárias para o peso e a altura dos pré-escolares das áreas de baixa renda estudadas. Na Tabela 2 estão descritas as mesmas médias encontradas para a população examinada de alto nivel sócio-econômico.

T A B E L A 1

Médias de peso e altura segundo faixa etária em pré-escolares de áreas de baixa rendo do Estado da São Paulo, 1977-79.

\begin{tabular}{|c|c|c|c|c|c|}
\hline \multirow{2}{*}{$\begin{array}{c}\text { Faixa etária } \\
\text { (anos) }\end{array}$} & \multirow[t]{2}{*}{$\mathbf{N}$} & \multicolumn{2}{|c|}{ Peso (kg) } & \multicolumn{2}{|c|}{ Altura (cm) } \\
\hline & & $\bar{x}$ & (D.P.) & $\vec{x}$ & (D.P.) \\
\hline $2[-\ldots 3$ & 99 & 12,78 & $(2,24)$ & 87,4 & $(6,1)$ \\
\hline $3 \ldots \ldots-1$ & 189 & 14,59 & $(2,11)$ & 95,2 & $(5,5)$ \\
\hline $4 \mid--\ldots 5$ & 276 & 16,27 & $(2,18)$ & 101,4 & $(5,9)$ \\
\hline $5:-\cdots \quad \cdots 6$ & 431 & 18,21 & $(2,47)$ & 108,3 & $(5,3)$ \\
\hline 61 - 7 & 374 & 19,77 & $(2,64)$ & 113,0 & $(5,4)$ \\
\hline
\end{tabular}

T A B E L A 2

Médias de peso e altura segundo faixa etária em pré-escolares de famílias de alto nivel sócio-econômico do município de São Paulo, 1978.

\begin{tabular}{|c|c|c|c|c|c|}
\hline \multirow{2}{*}{$\begin{array}{c}\text { - Faixa etária } \\
\text { (anos) }\end{array}$} & \multirow[t]{2}{*}{$\mathrm{N}$} & \multicolumn{2}{|c|}{ Peso (kg) } & \multicolumn{2}{|c|}{ Altura (cm) } \\
\hline & & $\bar{x}$ & (D.P.) & $\bar{x}$ & (D.P.) \\
\hline $21-\cdots n$ & 21 & 14,00 & $(1,07)$ & 92,5 & $(3,0)$ \\
\hline $3 \mid-\ldots--1$ & 40 & 16,12 & $(2,28)$ & 98,5 & $(3,9)$ \\
\hline $41-\cdots-5$ & 38 & 18,65 & $(2,91)$ & 106,0 & $(5,0)$ \\
\hline $5 !--6$ & 79 & 21,52 & $(2,92)$ & 113,6 & $(5,1)$ \\
\hline $61-7$ & 69 & 23,41 & $(4,09)$ & 117,3 & $(5,0)$ \\
\hline
\end{tabular}


MONTEIRO, C.A. et al. Estudo antropométrico-nutricional de pré-escolares üe áreas de baixa renda do Estado de Såo Paulo, Brasil. Rev. Śuude públ., S. Paulo, 16:1-16, 1984.

Com relaçāo ao peso, observa-se que as médias são sempre inferiores nas áreas de baixa renda, ampliando-se o diferencial cont o progredir da idade. A diterença desfavurável à baixa renda, que é de pouco mais du que um quilograma na idade dos 2 anos, chega, aos 6 anos, a quase $4 \mathrm{~kg}$.

Com relação à altura, ainda que em todas as faixas etárias as médias sejam sempre menores nas áreas de baixa renda, não se nota ampliação do diferencial, que fica sempre em torno de 4 ou $5 \mathrm{~cm}$.

A análise estatistica das diferenças entre as médias de peso e altura das duas populações revela difere!ıças significativas em todas as idades ( $p<0,05$ no caso da diferença de peso aos 2 anos, $p<0,001$ em todas as demais diferenças).

O quociente do peso de cada pré-escolar pela sua altura, expresso em quilogramas por centímetro, traduz o seu equilibrio pondo-estatural. As médias encontradas para estes quocientes nas diversas faixas etárias e nas duas populações estudadas acham-se descritas na Tabela 3. Nela se observa que as médias da relação peso altura são sistematicamente inferiores nas áreas de baixa renda. A diferença é mínima na idade dos 2 anos, $5 \mathrm{~g}$ para cada centimetro de altura, mas se amplia progressivamente nas subseqüentes idades, chegando a $25 \mathrm{~g}$ por centímetro aos 6 anos.

$A$ análise estatística das diferenças entre as médias da relação peso/altura nas duas populações revela diferenças significativas a partur dos 3 anos de idade ( $p<0,001$ em todas as diferenças).

A análise até aqui evidência condições destavoráveis dos pré-escolares das áreas Ge baixa renda, seja quando considerado seu peso, seja quando considerada sua altura. A consideração do fator idace sugere, entretanto, que peso e altura sejam diferentemente afetados durante os anos pré-escolares: o peso dando mostras de seguir-se deteriorando durante toda a idade pré-escolar e a altura aparentando ter seu déficit instalado fundamentalmente nos anos que precedem o periodo pré-escolar. $O$ comportamento da relação peso/altura, que piora evidentemente com o progredir da idade, reforça a hipótese de um comprometimento diferenciado de peso e de altura durante a idade pré-escolar. No sentido de verificar esta última hipótese é que são encaminhadas as análises de regressão executadas a seguir.

\subsubsection{Regressões de peso e altura em função da idade}

Funções matemáticas que expressem adequadamente o comportamento de medidas antropométricas, como peso e altura, em função da idađe, podem fornecer boas aproximações sobre como e em que velocidade se dá $\bigcirc$ crescimento em determinados períodos. A velocidade do crescimento, neste

\section{T A B E L A 3}

Média da relação peso/altura $\mathrm{kg} / \mathrm{cm}$ segundo faixa etária nas áreas de baixa renda e na população de alto nivel sócio-econômico.

\begin{tabular}{|c|c|c|c|c|c|c|}
\hline \multirow[t]{2}{*}{$\begin{array}{l}\text { Faixa etárla } \\
\text { (anos) }\end{array}$} & \multicolumn{3}{|c|}{ Áreas de baixa renda } & \multicolumn{3}{|c|}{$\begin{array}{c}\text { População de alto nível } \\
\text { sócio-econômico }\end{array}$} \\
\hline & $\mathbf{N}$ & $\bar{x}$ & (D.P.) & $N$ & $\vec{x}$ & (D.P.) \\
\hline $21--\infty$ & 99 & 0,146 & $(0,017)$ & 21 & 0,151 & $(0,009)$ \\
\hline $3 \mid-\ldots-4$ & 189 & 0,153 & $(0,153)$ & 40 & 0,163 & $(0,018)$ \\
\hline $41-\cdots-5$ & 276 & 0,160 & $(0,014)$ & 38 & 0,176 & $(0,022)$ \\
\hline $5 \mid--\longrightarrow 6$ & 431 & 0,168 & $(0,017)$ & 79 & 0,189 & $(0,021)$ \\
\hline $61-7$ & 374 & 0,174 & $(0,018)$ & 69 & 0,199 & $(0,030)$ \\
\hline
\end{tabular}


MONTEIRO, C.A. et al. Estudo antropométrico-nutricicnal de pré-escolares de áreas de baixa renda do Estado de São Paulo, Brasil. Rev. Saúde públ., S. Paulo, 18:1-18, 1984.

caso, é indicada pelo coeficiente de regressão, ou seja, pelo valor do parâmetro que na função matemática multiplica a variável idade. Este parâmetro, o coeficiente de regressão, será primordial na verificação da hipótese do diferente comprometimento que, na idade pré-escolar, teriam peso e altura.

Para se chegar às funções matemáticas capazes de exprimir o crescimento durante a idade pré-escolar, na baixa renda e no alto nivel sócio-econômico, os dados de peso e de altura foram plotados por computador em diagramas de dispersão segundo a jdade. A observação de configuração espacial da nuvem de pontos dos diagramas relativos a peso sugeriu que, em ambos os níveis sócio-econômicos, uma função de segundo grau do tipo $\mathrm{y}=\mathrm{a}+\mathrm{bx}^{2}$ pudesse explicar adequadamente a variação do peso (y) diante da jdade $(x)$. Já no caso dos diagramas relativos à altura, a configuração espacial sugeriu uma função linear do tipo $y=a+b x$, relacionando, nas duas populações, altura (y) à idade (x).

Antes de se efetivar as análises de regressão capazes de determinar quais os valores dos parâmetros $a$ e $b$, houve cuidado de verificar o comportamento da variabilidade do peso e da altura nas várias idades, uma vez que é condição indispensável para o modelo de regressão que a variância de $y$ seja constante, independendo de $x$. Esta condição, denominada homocedasticidade da variável dependente, não foi verificada, pois as variâncias do peso e da altura aumentavam com a idade nas duas populações, repetindo, aliás, comportamento já observado em populaçōes semelhantes às estudadas ${ }^{17}$. Em vista deste fato, recorreu-se ao método dos mínimos quadrados ponderados para análise de regressão ${ }^{13}$. Este método garante a condição de homocedasticidade ao ponderar os quadrados dos desvios, dando maior peso às observações de menor variância e menor peso às de maior variância.

$\mathrm{Na}$ Figura 1 acham-se as curvas de regressāo do peso em função da idade ob- servadas a partir das análises de regressão conduzidas separadamente nos dois niveis sócio-econômicos. $\mathrm{O}$ ajuste obtido pelas curvas pode ser considerado bom nos dois casos, uma vez que os coeficientes de determinação ( $\left.R^{2}\right)$ ultrapassaram 0,90, significando assim que os modelos adotados explicariam, em cada caso, mais de $90 \%$ da variabilidade observada nos pesos de pré-escolares. Por outro lado, a estatística $F$ que determina o significado estatístico dos coeficientes das regressões, e das próprias regressões, alcançou valores que excederam de muito os valores críticos previstos para o nível de significância de $\mathbf{5 \%}$ (nos dois casos $p<0,001$ ).

$\mathrm{Na}$ Figura 2 acham-se as retas de regres. são da altura em função da idade. Também neste caso, nas duas regressões, os coeficientes obtidos foram estatisticamente significativos ( $\mathrm{p}<0,001)$. Os ajustes, por sua vez, foram ainda mais satisfatórios com o coeficiente de determinação aproximando-se da unidade.

Em relação ao peso, é evidente a menor inflexão da curva que corresponde à baixa

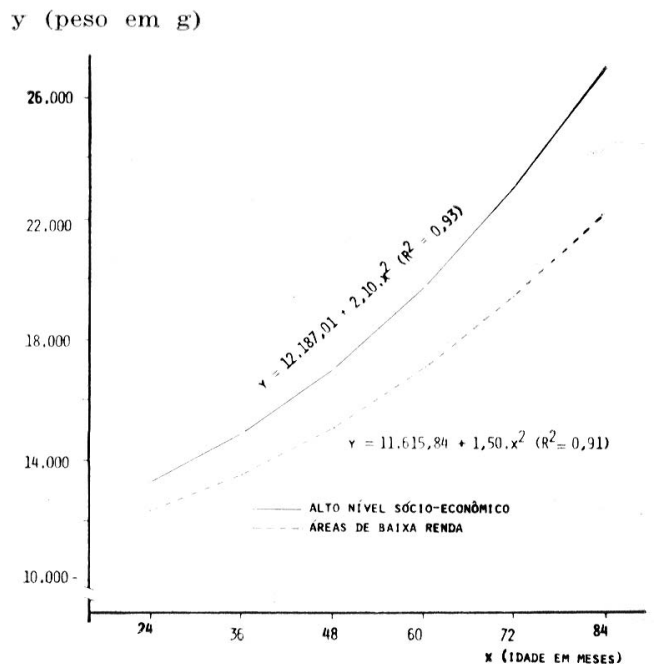

Fig. 1 - Curvas de regressão do peso de pré- escolares em função da idade nas áreas de baixa renda e na população de alto nivel sócio-económico. 
MONTEIRO, C.A. et al. Estudo antropométrico-nutricional de pré-escolares de áreas de baixa renda do Estado de São Paulo, Brasil. Rev. Saúde públ., S. Paulo, 18:1-18, 1984.

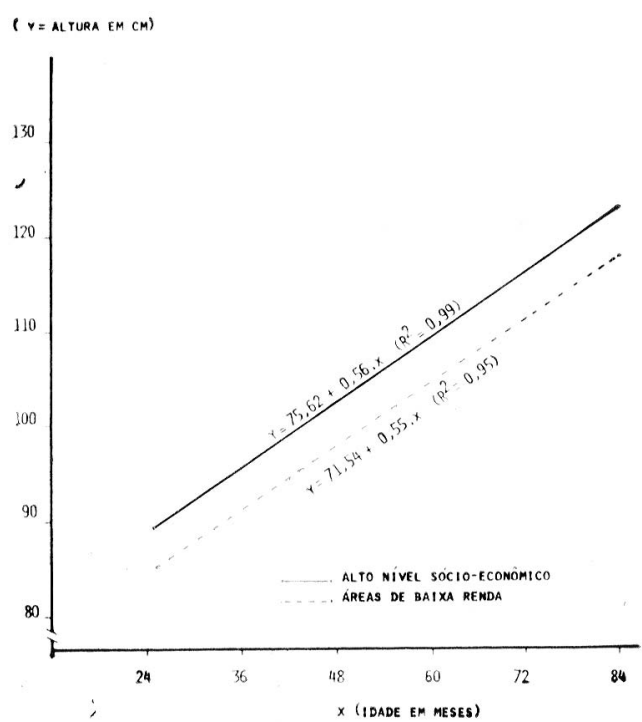

Fig. 2 - Retas de regressão da altura de pré-escolares em funçāo da idade nas áreas de baixa renda e na população de alto nível sócio-econômico.

renda. Esta menor inflexão è responsável por um aumento crescente do diferencial de peso que separa os dois níveis sócio-econômicos. Dos 24 aos 36 meses,o diferencial aumenta de $432 \mathrm{~g}$, dos 48 aos 60 meses, de $778 \mathrm{~g}$ e dos 72 aos 84 meses de $1.123 \mathrm{~g}$. As regressōes prevêem, por outro lado, um diferencial de $917 \mathrm{~g}$ no início da idade pré-escolar, e um diferencial jả de $4.805 \mathrm{~g}$ ao seu final.

Em relação à altura, nota-se que, embora partindo de situação inferior, a reta de regressão dá baixa renda mantém certo paralelismo com a reta de regressão do alto nivel sócio-econômico, não sugerindo, portanto, aumento do diferencial durante os anos pré-escolares. De fato as regressões prevêem durante as idades pré-escolares um diferencial de $4,3 \mathrm{~cm}$ aos 24 meses e de $4,9 \mathrm{~cm}$ as 84 meses.

A análise estatística das diferenças entre as duas populações, com relação à velocidade no ganho de peso e no ganho de altura, é conduzida através do teste da dife- rença entre dois coeficientes de regressão. No caso do ganho de peso, a análise revela que é significantemente menor $o$ coeficiente de regressão obtido na baixa renda $(p<0,001)$. No caso do ganho de altura, não foi registrada diferença signnificativa entre os coeficientes encontrados nos dois níveis sócio-econômicos $(\mathrm{p}=0,288)$.

\subsection{Avaliação a partir dos dados de perimetro braquial e dobra cutânea tricipital}

\subsubsection{Médias das áreas da seção transversal do braço nas diversas faixas etárias}

As médias obtidas nas diversas faixas etárias quanto à área total da seção transversal do braço e quanto às áreas "muscular" e "adiposa" são apresentadas nas Tabelas 4 (pré-escolares das áreas de baixa renda) e 5 (pré-escolares de familias de alto nível sócio-econômico).

Iniciando a comparação pela área total da seção transversal do braço, verifica-se que, em todas as faixas etárias, é inferior a média obtida na baixa renda. Observa-se, ainda, que o diferencial desfavorável à baixa renda progride uniforme e rapidamente no decorrer da idade pré-escolar, partindo de pouco mais de $1 \mathrm{~cm}^{2}$ na faixa dos 2 anos, mas já ultrapassando $5 \mathrm{~cm}^{2}$ na faixa dos 6 anos.

Em relação especificamente ao componente muscular da seção transversal do braço, observam-se áreas também sistematicamente menores para a baixa renda. $O$ "diferencial muscular", entretanto, aumenta apenas lentamente, $e$ de modo não uniforme, com a idade, progredindo menos de $1 \mathrm{~cm}^{2}$ dos 2 aos 6 anos.

Quanto ao componente adiposo da seção transversal do braço, aos 2 anos sua área é idêntica nos dois niveis sócio-econômicos. Aos 3 anos, instala-se pequeno diferencial desfavorável à baixa renda. A partir daí, este diferencial progride de modo rápido 
MONTEIRO, C.A. et al. Estudo antropométricu-nutricional de pré-escolares de áreas de baixa renda do Estado de São Paulo, Brasil. Rev. Saúde públ., S. Paulo, 18:1-18, 1984.

T A B E L A 4

Médias de áreas do braço segundo faixa etária em pré-escolares de áreas de baixa renda do Estado de São Paulo, 1977-79.

\begin{tabular}{|c|c|c|c|c|c|c|c|}
\hline \multirow[t]{2}{*}{$\begin{array}{l}\text { Faixa etária } \\
\quad(\text { anos) }\end{array}$} & \multirow[t]{2}{*}{$\mathbf{N}$} & \multicolumn{2}{|c|}{$\begin{array}{l}\text { Area muscular } \\
(\mathrm{cm} 2)\end{array}$} & \multicolumn{2}{|c|}{$\begin{array}{l}\text { Area adiposa } \\
(\mathrm{cm} 2)\end{array}$} & \multicolumn{2}{|c|}{$\begin{array}{c}\text { Area total do braço } \\
(\mathrm{cm} 2)\end{array}$} \\
\hline & & $\bar{x}$ & (D.P.) & $\bar{x}$ & (D.P.) & $\bar{x}$ & (D.P.) \\
\hline 2 í_..... 3 & 99 & $13, \mathbf{5}$ & $(2,1)$ & 6,3 & $(1,8)$ & 19,8 & $(3,3)$ \\
\hline $31 \longrightarrow 4$ & 187 & 14,4 & $(2,1)$ & 6,7 & $(1,9)$ & 21,1 & $(3,3)$ \\
\hline $41-\longrightarrow 5$ & 276 & 15,2 & $(2,1)$ & 6,8 & $(2,0)$ & 22,0 & $(3,1)$ \\
\hline $51--\cdots \cdots$ & 429 & 16,8 & $(2,9)$ & 6,4 & $(2,3)$ & 22,7 & $(4,2)$ \\
\hline $61-7$ & 373 & 16,7 & $(2,3)$ & 6,7 & $(2,6)$ & 23,5 & $(3,9)$ \\
\hline
\end{tabular}

T A B E L A 5

Médias de áreas do braço segundo faixa etária em pré-escolares de familias de alto njvel sócio-econômico do municipio de São Paulo, 1978.

\begin{tabular}{|c|c|c|c|c|c|c|c|}
\hline \multirow[t]{2}{*}{$\begin{array}{l}\text { Faixa etária } \\
\text { (anos) }\end{array}$} & \multirow[t]{2}{*}{$\mathbf{N}$} & \multicolumn{2}{|c|}{$\begin{array}{l}\text { Área muscular } \\
(\mathrm{cm} 2)\end{array}$} & \multicolumn{2}{|c|}{$\begin{array}{l}\text { Area adiposa } \\
(\mathrm{cm} 2)\end{array}$} & \multicolumn{2}{|c|}{$\begin{array}{l}\text { Area total do braço } \\
(\mathrm{cm} 2)\end{array}$} \\
\hline & & $\bar{x}$ & (D.P.) & $\vec{x}$ & (D.P.) & $\bar{x}$ & (D.P.) \\
\hline 2 | & 21 & 14,8 & $(1,7)$ & 6,3 & $(1,3)$ & 21,1 & $(2,3)$ \\
\hline $3:-4$ & 39 & 15,8 & $(2,7)$ & 7,2 & $(2,3)$ & 22,9 & $(4,6)$ \\
\hline 4 & 38 & 17,1 & $(2,1)$ & 8,2 & $(3,9)$ & 25,3 & $(5,3)$ \\
\hline 5 & 79 & 18,0 & $(2,2)$ & 9,1 & $(3,1)$ & 27,2 & $(4,5)$ \\
\hline 6 - 7 & 69 & 18,8 & $(2,8)$ & 10,1 & $(5,0)$ & 28,9 & $(6,9)$ \\
\hline
\end{tabular}

e uniforme até atingir, na faixa dos 6 anos, $3,4 \mathrm{~cm}^{2}$. E interessante observar que, na baixa renda, a média da "área adiposa" do braço se mantém praticamente estacionária durante toda a idade pré-escolar.

A análise estatística das diferenças entre as médias das áreas do braço das duas populações revela para "área muscular" diferenças significativas em todas as idades ( $p<0,02$ aos 2 anos e $p<0,001$ nas demais idades). Para "área adiposa" diferenças significativas ocorrem apenas a partir dos 4 anos $(p<0,001)$ e para área total apenas a partir dos 3 anos ( $p<0,01$ aos 3 anos e $p<0,001$ nas demais idades).

Desta forma a análise efetuada parece indicar que, nas áreas de baixa renda, as crianças começariam o período pré-escolar já deficitárias em tecido muscular e, posteriormente, percorreriam os anos pré-escolares acumulando déficits sobretudo de tecido adiposo. Esta hipótese será verificada por meio das análises de regressão que são apresentadas a seguir.

\subsubsection{Regressões das áreas do braço em função da idade}

Com as análises de regressão das áreas do braço em função da idade, pretende-se conhecer a velocidade da expansão dos tecidos muscular e adiposo entre os pré-escolares das áreas de baixa renda $\mathrm{e}$ entre os pré-escolares de alto nivel sócio-econômico. 
MONTEIRO, C.A. et al. Estudo antropométrico-nutricional de pré-escolares de áreas de baixa renda do Estado de Săo Paulo, Brasil. Rev. Saúde públ., S. Paulo, 18:1-18, 1984.

Os diagramas de dispersão das áreas do braço segundo a idade sugeriram que, em ambos os níveis sócio-econômicos, funções lineares do tipa $y=a+b x$ pudessem expressar adequadamente a variação das áreas conforme a idade.

Tal como os dados de peso e altura, verificou-se que, nas duas populações, as áreas do braço apresentavam variância que aumentava com a idade. Em função deste fato, as análises de regressão para as áreas foram também conduzidas com o auxilio do método dos mínimos quadrados ponderados, já referido anteriormente.

$\mathrm{Na}$ Figura 3, acham-se as retas de regressão que, nas duas populações, expressam a relação entre o valor das áreas do braço e a idade. Ajustes razoáveis $\left(R^{2}>0,70\right)$ foram obtidos para "área muscular" nas duas populações e para área total na baixa renda. Ajustes intermediários $\left(\mathrm{R}^{2} \mathrm{em}\right.$ torno de 0,50 ) foram obtidos para área total na baixa renda e para "área adiposa" no alto nível sócio-econômico. Ajuste sofrivel $\left(R^{2}=0,13\right)$ foi obtido no caso da" "área adiposa" na baixa renda. A análise estatística dos coeficientes de regressão obtidos (e, portanto, das próprias regressōes) revelou significado estatístico $(p<0,001)$ em todas as situações, exceto na relação entre "área adiposa" e idade na baixa renda $(0,05<p<0,10)$. Este último fato implicaria aceitar que nas áreas de baixa renda estudadas a "área adiposa" não se expande com o progredir da idade pré-escolar.

Observando-se a Figura 3 , verifica-se que tanto para a área total da seção transversal do braço como para seus componentes muscular e adiposo é sempre menor a inflexão das retas que representam a baixa renda. A comparação mais desvantajosa ocorre quando se trata especificamente da "área adiposá". É interessante observar que, no nível sócio-econômico alto, o crescimento da "área adiposa" praticamente acompanha o ritmo de expansão da "área muscular". Já na baixa renda, o valor da

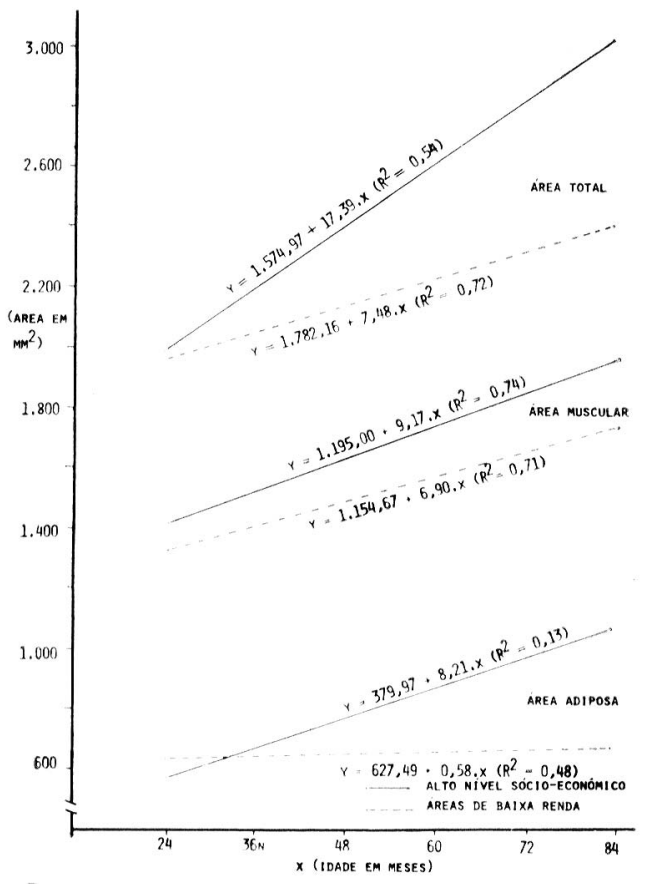

Fig. 3 - Retas de regressão das áreas do braço de pré-escolares em função da idade nas áreas de baixa renda e na população de alto nível sócio-econômico.

"área adiposa" se mantém estacionário du. rünte toda a idade pré-escolar, não acompanhando a expansão da "área muscular" que se dá, inclusive, em velocidade razoavel. mente próxima à observada no alto nivel sócio-econômico.

Outra observação importante, indicada pelas regressões, é que o déficit da "área adiposa", na baixa renda, tem seu iníc1o apenas na idade pré-escolar, enquanto que a "área muscular", que é menos comprometida durante aquele período, já carrega importante déficit aos 24 meses de idade.

A análise estatística das diferenças encontradas entre os dois niveis sócio-econômicos com relação às velocidades de expansão da área total da seção transversal do braço e da "área muscular" acusou significado estatístico em ambos os casos ( $p<0,001$ e $p<0,01$ respectivamente). A 
MONTEIRO, C.A. et al. Estudo antropométrico-nutricional de pré-escolares de áreas de baixa renda do Estado de São Paulo, Brasil. Rev. Saúde públ., S. Paulo, 18:1-18, 1984.

análise estatistica não foi necessária com relação à diferença na expansão da "área adiposa", visto haver-se demonstrado ser o coeficiente de regressão na baixa renda não significativamente diferente de zero.

$$
4 \text { - COMENTÁRIOS }
$$

O objetivo primordial do estudo foi o exame antropométrico do estado nutricional de uma população de pré-escolares. Não houve preocupação em identificar e quantificar os pré-escolares desnutridos, mas sim em avaliar as condições nutricionais do conjunto deles. Houve interesse especifics em esclarecer dois pontos que têm recebido pouca atenção em investigações similares: a cronologia do comprometimento do crescimento e sua especificação em termos dos tecidos atingidos.

Os comentários que se seguem procurarão abranger três tópicos: a propriedade da metodologia utilizada, os achados principais e sua possivel extensão a outras populações de pré-escolares e as implicações que decorrem do estudo.

\subsection{Metodologia utilizada}

Há dois aspectos que devem ser salitntados em relação à metodologia que foi utilizada para descrever o estado nutricional: a pertinência do exame antropométrico e a validade do padrão de referência.

O uso do exame antropométrico como instrumento diagnóstico do estado nutricional apoia-se na evidència de que a redução da velocidade do crescimento é a manifestação mais precocemente detectável de que o organismo infantil não esteja vivendo $\mathrm{sob}$ adequadas condiçōes nutricionais ${ }^{2,28}$. Neste sentido, poder-se-ia entender a redução da velocidade do crescimento como uma eficaz reação adaptativa de que o organismo lançaria mão, sempre que a escassez de nutrientes colocasse em risco suas funçōes mais nobres, ou mesmo, sua própria sobre- vivência 28. Além da maior sensibilidade sobre outros métodos diagnósticos como o exame de sinais clínicos e os exames bioquímicos, o exame antropométrico apresenta vantagens de menor custo, mais facilidade de padronização e maior factibilidade de ser operado em condições de campo ${ }^{15}$.

O padrão antropométrico utilizado como referência se baseou nas medidas de pré-escolares pertencentes a familias de alto nivel sócio-econômico. Esta condição, por si, deve garantir àqueles pré-escolares crescimento livre de impedimentos ambientais. Para verificação desta hipótese e validação do padrão utilizado, seus valores médios de peso e de altura foram compa-

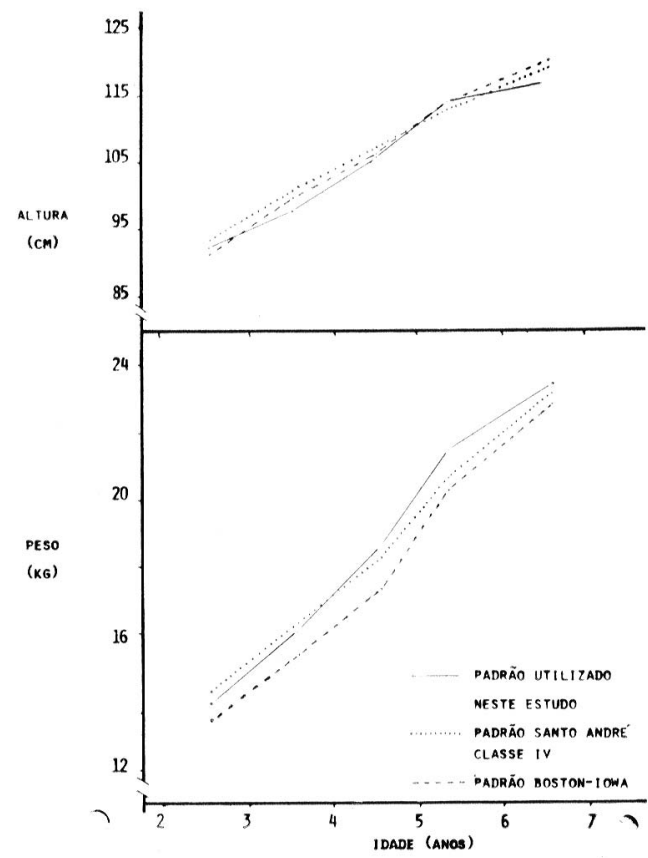

Fig. 4 - Medianas de peso e altura no padrão de referência utilizado e nos padrões "Santo André Classe IV" e "Boston-Iowa". (Para o padrăo "Santo André Classe IV" e para o padrăo "Boston-Iowa" 28 foi considerada a média aritmética entre as medianas registradas para os dois sexos). 
MONTEIRO, C.A. et al. Estudo antropometrico-nutricional de pré-escolares de áreas de balsa renda do Estado de São Paulo, Brasil, Rev. Saúde públ., S. Paulo, 18:1-18, 1984.

rados aos mesmos valores encontrados $\mathrm{cm}$ dois padrões antropométricos de amplo uso: "Santo André Classe IV"1i e "Boston-lowa"29 (Fig. 4). "Santo André Classe IV" foi construido a partir de crianças brasileiras de famílias de alto poder aquisitivo, de dois municípios do Estado de São Paulo, e é o padrão adotado pela Sociedade Brasileira de Pediatria 10. "Boston-Iowa" foi construido a partir de crianças americanas de familias brancas de classe média (de Boston até os 5 anos de idade e de Iowa dos 5 anos em diante) e é, possivelmente, o padrão de uso mais extensivo em todo 0 mundo.

Diferenças relativamente pequenas separam o padrão utilizado dos outros dois padrões. A pequena ordem de grandeza das diferenças fica evidente quando a magnitude das mesmas é comparada à magnitude dos déficits encontrados na população de baixa renda examinada.

Uma vez constatado que o crescimento dos pré-escolares do padrão de referência provavelmente traduz a máxima expressão do seu potencial genético, restaria verificar se a população de pré-escolares das áreas de baixa renda teria idêntico potencial de crescimento. Ainda que seja bastante complexa uma resposta categórica a esta questão, considerando os grupos étnicos que constituem as duas populações (exclusivamente brancos na população de referência e brancos, negros e mulatos na população de baixa renda) e considerando o atual estágio de conhecimento sobre o potencial genético de crescimento de diferentes raças ${ }^{3}$, poder-se-ia admitir, como hipótese de trabalho mais convincente, que o potencial de crescimento da população de baixa renda seja muito próximo, ou mesmo idêntico, ao potencial de crescimento da população de referência.

E importante assinalar que todas as considerações feitas acima se referem às medidas de peso e de altura. Em relação às áreas "muscular" e "adiposa" do braço, dado o menor volume de estudos realizados e a ausência de padrões internacionalmente aceitos, é difícil examinar a validade do padrão utilizado. $\mathrm{O}$ aspecto mais importante a ser mencionado nesta questão, e que se constitui em um avanço obtido por este estudo, refere-se à utilização de padrões de referência para várias medidas, incluindo as áreas do braço, provenientes de uma mesma população de alto nivel sócio-econômico. A ausência desta condição teria tornado praticamente impossivel o exame integrado dos resultados provenientes das várias medidas.

\subsection{Extensäo dos resultados}

As análises efetuadas a partir dos dados de peso e altura indicam que as crianças das áreas de baixa renda chegam ao final da idade pré-escolar com um pronunciado retardo no seu crescimento. De acordo com os valores previstos pelas análises de regressão, ao chegar aos 7 anos, aquelas crianças teriam em relação a uma população bem nutrida, déficits aproximados de $5 \mathrm{~cm}$ de altura e de $5 \mathrm{~kg}$ de peso.

Procurando verificar, por meio das mesmas análises de regressão, em que medida aqueles déficits observados aos 7 anos ocorreriam durante a idade pré-escolar, identificam-se cronologias diferentes para os déficits de altura e de peso. O déficit de altura ocorreria fundamentalmente antes da idade pré-escolar, pois aos 24 meses de idade quase $90 \%$ daquele déficit já estaria estabelecido. $O$ déficit de peso, por sua vez, ocorreria predominantemente nos próprios anos pré-escolares, onde se localizaria mais de $80 \%$ do déficit acumulado aos 7 anos. E interessante notar que, na idade pré-escolar, as crianças das áreas de baixa renda diferem significativamente das crianças de alto nivel sócio-econômico apenas quanto ao ganho de peso, não chegando a ser significativa a diferença observada quanto ao ganho de altura.

A questão que agora se coloca é saber até que ponto os resultados obtidos com 
MONTEIRU. C.A. et al. Estudo antropométrico-nutricional de pré-escolares de áreas de baixa renda do Estado de São Paulo, Brasil, Rev. Saúde públ., S. Paulo, 18:1-18, 1984.

a análise dos dados de peso e altura da população examinada poderiam ser encontrados em outras populaçốes brasileiras de pré-escolares.

O exame da questão é difícil, pois a maioria dos inquéritos nutricionais realizados no Brasil tem utilizado os dados de peso e altura dos pré-escolares com o fim exclusivo de estabelecer a prevalência de desnutridos. No processo de chegar a esta prevalência, os dados de peso e de altura são convertidos em adequações percentuais que, a partir de determinados níveis críticos, passam a classificar o indivíduo como desnutrido. A definição arbitrária destes niveis, feita sem levar em consideração a diferente variabilidade das medidas nas várias idades, impede que seja examinada a cronologia dos diferentes déficits antropométricos.

Uma aproximação parcial à questão da possivel extensão dos resultados pode ser conseguida a partir das médias de peso e de altura publicadas pelo Instituto Brasileiro de Geografia e Estatistica (IBGE) 6 para as diversas regiōes brasileiras. Estas medidas procedem do Estudo Nacional da Despesa Familiar (ENDEF) ${ }^{4}$, que o IBGE realizou em amostras representativas das várias regiōes brasileiras, entre 1974 e 1975. Em função de o ENDEF não ter sido exatamente um inquérito antropométrico e, portanto, não ter contado com o rigor metodológico necessário 5 , os resultados publicados pelo IBGE devem ser encarados com cautela, indicando mais tendências das medidas do que seus valores reais. Sérão aqui analisados os resultados referentes à Região II (Estado de São Paulo), onde toram examinados 3.371 pré-escolares, e à Região V (Estados do Nordeste), onde toram examinados 11.279 pré-escolares. A escolha da Região $V$ foi feita por ser esta regiăo brasileira onde são relatadas as maiores prevalências de desnutrição ${ }^{20}$,

$\mathrm{Na}$ Figura 5, estão graficamente representadas as diferenças existentes, nas várias faixas etárias, entre as médias de peso e de altura publicadas para as Regiōes II e $\mathrm{V}$ e as médias de peso e de altura do padrão de referência. Ainda na mesma Figura, foram acrescentadas as diferenças encontradas quando a população de baixa renda estudada foi comparada ao padrão.

O primeiro ponto a chamar a atenção é a maior magnitude dos déficits de peso $\mathbf{P}$ de altura da Região $V$, que excedem em cerca de duas vezes os déficits constatados nas áreas de baixa renda investigadas. Os déficits encontrados para o Estado de Săo Paulo como um todo (Região II) não chegam a diferenciá-lo da situação das áreas de baixa renda estudadas.

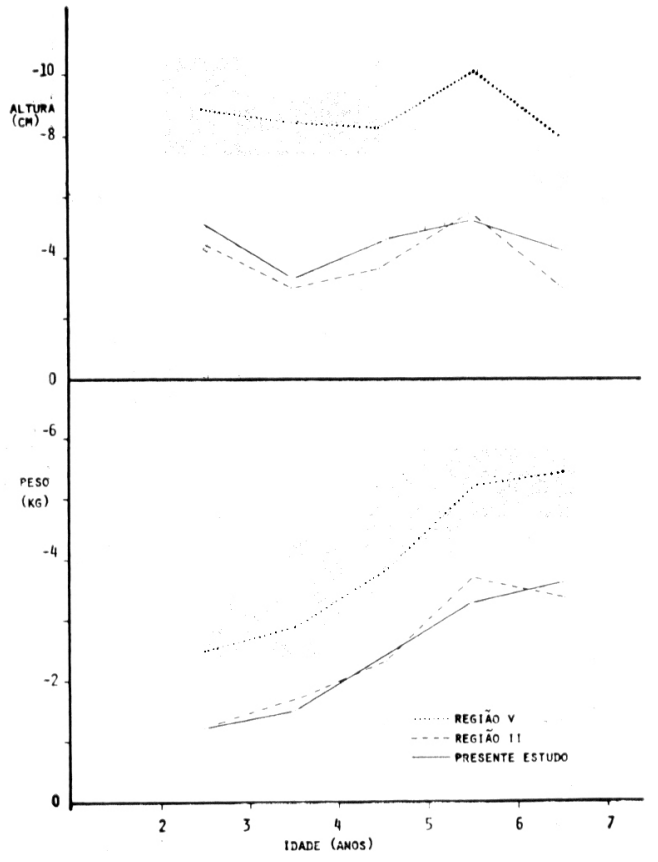

Fig. 5 - Diferenças $(\Delta)$ em relação ao padrăo de referência das médias de peso e de altura observadas na Região II (Estado de São Paulo), na Região V (Estados do Nordeste) e no presente estudo. (Para as regióes II $\mathrm{e} V$, as diferenças foram calculadas a partir da média aritmética entre as médias registradas para os dois sexos 6 ). 
MONTEIRO C.A, et al. Estudo antropomitrico-nutricional de pré-escolares de áreas de baixa renda do Estado de São Paulo, Brasil, Rev. Saúde públ., S. Paulo, 18:1-18, 1984.

Mais importante do que comparar a magnitude dos déficits de peso e de altura é comparar a evolução dos mesmos no decorrer da idade pré-escolar. Sob este aspecto, é fácil verificar que os déficits de peso e de altura evoluem nas Regiōes II e $V$ de forma semelhante à observada nas áreas de baixa renda. Nas três populações focalizadas, observa-se que, enquanto os déficits de altura se mantêm relativamente estáveis, os déficits de peso se elevam progressivamente com o correr da idade. A observação deste fato levaria a supor que o comprometimento cronologicamente diferenciado do peso e da altura, com agravos mais precoces da última e mais tardios do primeiro, não seria um achado restrito às áreas de baixa renda investigadas no Estado de São Paulo, mas que, eventualmente, poderia ser encontrado em outras regiōes brasileiras.

As análises efetuadas a partir dos indicadores antropométricos das áreas do braço indicam que as crianças das áreas de baixa renda chegam ao final da idade pré-escolar com aqueles indicadores bastante inferiorizados em relação à população de referência. De acordo com os valores previstos pelas análises de regressão, ao chegar aos 7 anos, aquelas crianças acumulariam déficits de "área muscular" de $2,3 \mathrm{~cm}^{2}$ e de área adiposa" de $4,0 \mathrm{~cm}^{2}$. As mesmas análises de regressão indicam, ainda, que o déficit de "área adiposa" registrado aos 7 anos ocorreria integralmente durante os anos pré-escolares, uma vez que aos 24 meses a "área adiposa" daquelas crianças não se diferenciaria do padrão de referência. Quanto ao déficit de "área muscular", o mesmo ocorreria parte nos anos pré-escolares, parte antes dos 24 meses. E interessante notar que durante o periodo pré. -escolar, tanto a expansão da "área adiposa" quanto a expansão da "área muscular" são significativamente inferiores às expansões observadas na população de referência, ainda que no caso da "área muscular" o nível de significância da diferença fique apenas entre $1 \%$ e $5 \%$.
A possível extensão dos resultados da análise das áreas do braço para outras populações brasileiras não pode ser verificada porque inexistem estudos que tenham examinado aqueles indicadores.

Uma comparação interessante pode ser feita com uma população de 1.240 pré-escolares pertencentes a famílias de baixo nível sócio-econômico da Guatemala, onde, simultaneamente aos dados de peso e altura ${ }^{32}$, foram coletados dados referentes às áreas do braço ${ }^{18}$.

Em relação aos dados de peso e de altura, - cálculo das diferenças existentes entre as médias dos pré-escolares da Guatemala e as médias do padrão de referência adotado no presente estudo revela déficits para a Guatemala semelhantes aos observados para a Região V do Brasil (Estados do Nordeste). A evolução dos déficits com o decorrer da idade pré-escolar também se assemelha à observada na Região $\mathrm{V}$ : enquanto $\rho$ déficit de altura é relativamente estável, em torno de $10 \mathrm{~cm}$, o déficit de peso progride com a idade, saltando de 3 para $6 \mathrm{~kg}$.

$\mathrm{Na}$ Figura 6 estão graficamente representadas as diferenças existentes, nas várias faixas etárias, entre as médias das áreas do braço da população guatemalteca e as médias da população de referência utilizada no presente estudo. $\mathrm{Na}$ mesma Figura, são colocadas as diferenças encontradas quando a população estudada das áreas de baixa renda foi comparada à população de referência.

Como era de se esperar, ambos os déficits de "área muscular" e de "área adiposa" assumem maior magnitude na população da Guatemala do que nas áreas de baixa renda investigadas no Estado de São Paulo. A observação da evolução dos referidos déficits no decorrer da idade pré-escolar mostra, entretanto, tendências semelhantes nas duas populaçōes. Em ambas, os déficits de "área adiposa" se elevan uniforme e expressivamente com a idade, enquanto pouco ou nada progridem os déficits de "área mus- 
MONTEIFo, C.A. et al. Estudo antropométric j-nutricional ảe pré-escolares de áreas de baixa renda do Estado de São Paulo, Brasil. Rev. Saũde públ., S. Paulo, 18:1-18, 1984.

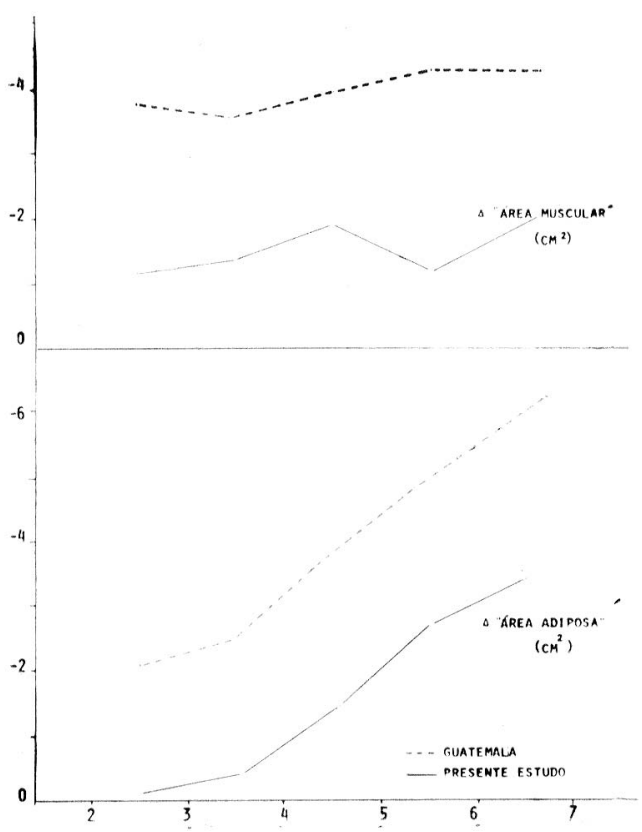

Fig. 6 - Diferenças $(\Delta)$ em relação ao padrão da referência das médias das áreas "muscular" e "adiposa" do braço observadas na Guatemala e no presente est"do. (Para a Guatemala, as diferenças com o padrão foram calculadas a partir da média aritmética entre as médias registradas para os dois sexos 18).

cular". Em função destas evoluções semelhantes, dos 4 para os 5 anos, em ambas as populações os déficits de "área adiposa" passam a predominar sobre os déficits de "área muscular".

Os dados relativos às áreas do braço, que se observam na Guatemala, sugeririam, portanto, que o comprometimento cronologicamente diferenciado dos componentes muscular e adiposo daquelas áreas não seja fato restrito à população estudada no Estado de São Paulo.

\subsection{Implicaf̧ões decorrentes}

A partir dos resultados que descrevem a condiçăo nutricional dos pré-escolares examinados emergem uma série de evidências, possivelmente generalizáveis a outras populações de baixo nível sócio-econômico. Baseadas nestas evidências, algumas hipóteses poderiam ser formuladas para futura averiguação em estudos de epidemiologia da desnutrição e de avaliação do estado nutricional. Algumas recomendações poderiām também ser feitas quanto à formulação e à avaliação de programas de nutrição.

Em relação à epidemiologia da desnutrição, há indicações de que a interação agente-hospedeiro responsável pelo aparecimento da desnutrição ocorra de maneira diferentes na idade pré-escolar e no periodo precedente. Até os 2 anos, daquela interação resultariam transtornos nutricionais que prejudicariam sobretudo a sintese de proteínas, retardando o crescimento em altura e a expansão do tecido muscular. Já no periodo pré-escolar, a sintese de proteinas evoluiria mais favoravelmente, sem permitir a recuperação dos déficits pregressos, mas sem determinar novos déficits importantes. No periodo pré-escolar, da interação agente-hospedeiro, resultariam prejuizos sobretudo à síntese das reservas calóricas representadas pelo tecido adiposo, cuja expansão não acompanharia a expansão dos demais tecidos. Haveria ai que investigar quais modificaçōes, a nivel do agente ou a nivel do hospedeiro seriam responsáveis pelas diferenças observadas nos dois períodos. A nivel do agente deveriam ser examinadas em detalhe as adequações calórica e protéica das dietas oferecidas às crianças, antes e durante a idade pré-escolar, assim como a diferente repercussão de eventuais doenças infecciosas. A nível do hospedeiro, haveria que se considerar a eficácia dos diferentes mecanismos adaptativos do organismo nos dois períodos de idade.

Em relação à avaliação do estado nutricional, as evidências encontradas pelo estudo indicam, inicialmente, que o exame antropométrico do peso e da altura pode ser enriquecido e complementado pelo exame simultâneo do perímetro braquial e da dobra 
MONTEIRC, C.A. et al. Estudo antropométrico-nutricional de pré-escolares de áreas de baixa renda đo Estado de São Paulo, Baas:l. Rev. Saúde públ., S. Paulo, 18:1-18, 1984.

cutânea tricipital. Por outro lado, há tambẻm indicações de que os dados de peso habitualmente colhidos na idade pré-escolar devam retratar predominantemente o estado das reservas calóricas das crianças, não revelando a situaçẳo da expansão de seus tecidos constituídos principalmente de proteínas. Antés dos dois anos, é provável que aqueles mesmos dados de peso reflitam globalmente o crescimento da criança. Outra evidência interessante revelada pelo estudo seria a de que a relação peso/altura baixa na idade pré-escolar mais do que refletir a natureza atual da desnutrição, como sugerem vários autores ${ }^{23,31}$, indicaria - comprometimento das reservas çalóricas diante do crescimento propriamente dito. Por outro lado, relações peso/altura normais antes dos 2 anos não garantiriam ausência de processo atual de desnutrição, mas, sim, poderiam indicar que o agravo nutricional estivesse atuando de forma a comprometer globalmente a velocidade do crescimento.

Em relação à formulação de programas de nutriçăo, as evidências sugerem que a concentração dos esforços deva ser dirigiđa para as idades anteriores aos 2 anos, uma vez que parece ser ali que o arcabouço do organismo se compromete de modo irrever- sível *. Nestas idades anteriores aos 2 anos, o conteúdo e a eficácia dos programas muito se beneficiariam dos achados de investigações que situassem a responsabilidade da dieta e das doenças infecciosas na vulnerabilidade aparentemerite maior do organismo. Uma vez concebidos e implantados programas que garantissem um adequado estado de nutrição até os 2 anos, estaria facilitada a tarefa de formular programas de nutrição para o período prê-escolar. Neste período, porque são predominantemente as reservas calóricas que não se expandem a contento, bastaria garantir às crianças um pequeno acréscimo na quantidade dos alimentos que elas já habitualmente consomem. Sendo menos complexas as atividades dirigidas propriamente à nutrição, haveria mais condiçōes para se implementar, no periodo pré-escolar, outras atividades essenciais ao desenvolvimento da criança, como as atividades relacionadas ao desenvolvimento psicológico.

$\mathrm{Na}$ avaliação do impacto que programas de nutrição poderiam exercer sobre o estado nutricional de crianças, as evidências obtidas indicam que, no período pré-escolar, a referida avaliação deveria se basear nos indicadores peso/idade e peso/altura.

\footnotetext{
* Na forma como foi concebido, o estudo não permite especificar em que idades, antes dos 2 anos, concentrar-se-ia o comprometimento que já está estabelecido aos 2 anos. Em uma outra investigação que os autores vêm realizando a partir de crianças de zero a dois anos de áreas de baixa renda do município de são Paulo, metodologia semelhante à utilizada no presente estudo indica que o retardo no crescimento observado aos 2 anos ocorre predominantemente entre os 8 e os 24 meses.
} 
MONTEIRO, C.A. et al. Estudo antropometrico-nutricional de pré-escolares de áreas de baixa renda do Estado de São Paulo, Brasil. Rev. Saúde públ., S. Paulo, 18:1-18, 1984.

MONTEIRO, C.A. et al. [An anthropometric-nutrition study of pre-school chlldren in low income group areas of the State of $\mathbf{S}$. Paulo, Brazil]. Rev. Saúde públ., S. Paulo, 18:1-18, 1984.

ABSTRACT: In order to evaluate nutritional status at pre-school age in low income areas of the State of $\mathbf{S}$. Paulo, 1,359 children ranging from two to six years underwent an anthropometric examination which included weight and height and measurements of the muscular and fatty areas of the transversal section of the left arm. The analysis of the measurements was made by comparison with measurements taken simultaneously among a population of pre-school children of high socio-economic standing in the county of $\mathbf{S}$. Paulo. Averages according to age were compared and then, by regression analysis according to age, the rates of "growth" of the various measurements were also compared. The analyses indicate that towards the end of pre-school age the children belonging to low income areas present considerable retardation in their growth (approximately $5 \mathrm{~cm}$ in height and $5 \mathrm{~kg}$ in weight). The transversal section of the arm of these children, at the same period, was reduced both in rigard to muscular and fatty tissue (about $2 \mathrm{~cm}^{2}$ and $4 \mathrm{~cm}^{2}$, respectively). The same analyses indicate different chronological timings as to the appearance of the deficits encountered during the final stages of pre-school age. Thus, the height as well as the arm muscular area deficits occur predominantly before two years of age whilst the weight and the arm fatty tissue area deficits occur mainly at pre-school age. The data obtained suggest that before two years of age the interaction agent-host responsible for the appearance of malnutrition causes damage, above all, to protein synthesis. Throughout pre-school age that interaction damages, principally, the caloric reserve synthesis. Alterations regarding the agent and/or at the level of the host could be responsible for the differences observed in both periods. So as better to understand them, factors such as caloric and proteic adequacy of the diets, the incidence and severity of infectious diseases and the adaptative mechanisms of the body should be investigated. In any case, the diversity of deficiencies in the nutritional status in both periods should be taken into consideration during the formulation of nutrition programmus directed to children of different ages.

UNITERMS: Anthropometry. Pre-school children. Nutritional status. Malnutrition.

\section{REFERENCIAS BIBLIOGRAFICAS}

1. ARROYAVE, G. \& CAStellanos, H. Role of the adrenal cortical system in the response of children to severe malnutrition. Amer. J. olin. Nutr., 9:186-95, 1961.

2. COMITE MIXTO FAO/OMS DE EXPERTOS EN NUTRICION, $80^{\circ}$ Ginebra, 1970; La desnutricion proteico-calorica, parte II. Ginebra, Organización Mundial de la Salud, 1972, p. 36-89. (OMS - Ser. inf. tecn., 477).

3. EVELETH, P.B. \& TANNER, J.M. Worldwide variation in human growth. London, Cambridge University Press, 1976.
4. FUNDAÇÃO IBGE. Estudo Nacional da Despesa Familiar - ENDEF': manual de instrugzes. Rio de Janeiro, 1974.

5. FUNDAÇAO IBGE. Consumo alimentar $e$ antropometria. Rio de Janeiro, 1977. (Estudo Nacional da Despesa Familiar, v. 1. Dados preliminares, t. 1).

6. FUNDAÇÃO IBGE. Perfil estatístico de criancas e mães no Brasil. Rio de Janeiro, IBGE/UNICEF, 1979.

7. GANDRA, Y.R. Asistencia alimentaria por medio de centros de educación y alimentación del pre-escolar. Bol. Ofic. sanit. panamer., $74: 302-14,1973$.

8. GOMEZ, F. Desnutrición. Bol. med. Hosp. infant., Mexico, 8:543-51, 1946. 
MONTEIRo, C.A. et al. Estudo antropométrico-nutricional de pré-escolares de áreas de baixa renda do Estado de São Paulo, Brasil. Rev. Saúde públ., S. Paulo, 18:1-18, 1984.

9. GRUPO DE PESQUISA DE CIENCIAS SOCIAIS EM NUTRIÇAO INAN-FINEP-IBGE, Relaioria final. Rio de Janeiro, 1980, v. 1.

10. GRUPO DE TRABALHO PARA O ESTUDO DA DESNUTRIÇAO DA SOCIEDADE BRASILEIRA DE PEDIATRIA. Avaliacão do estado nutricional. In: Nóbrega, F.J. Desnutrição intra-uterina e pos-natal. São Paulo, Panamed Editorial, 1981. p. 118-9.

11. GURNEY, J.M. The arm circunference as a public health index of protein-calorie malnttrition of early childhood: (XIII) field experience in Abeokuta, Nigéria (with special reference to differentiating protein and calorie reserves). $J$. trop. Pediat., 15:225-32, 1969.

12. HEYMSFIELD, S.B. et al. A radiographic method of quantitying protein-calories undernutrition. Amer. J. clin. Nutr., $32: 697-702,1979$.

13. HOFFMANN, R. \& VIEIRA, S. Análise de regressāo: uma introdugão a ecometria. São Paulo, Editora Hucitec/Ed. USP, 1977.

14. JELLIFFE, D.B. Evaluación del estado de nutrición de la comunidad. Ginebra Organizacion Mundial de la Salud, 1968. (OMS - Ser. Monogr., 53).

15. JELLIFFE, E.F.P. \& JELLIFFE, D.B. The arm circunference as a p-blic health index of protein-calorie malnutrition of early childhood: (I) background. $J$. trop. Pediat., 15:179-88, 1969.

16. JORDAN, $J$, et al. Investigacíón nacional sobre crescimiento y desarollo, Cuba, 1972-1974. III - Normas nacionales de peso y talla, Rev. cuba. Pediat. 50:425-50. 1978.

17. MARQUES, R.M. et al. Creicimento $e$ desenvolvimento pubertario em criancas $e$ adolescentes brasileiros. II - Altura e peso. São Paulo, Editora Brasileira de Ciências, 1982.

18. MARTORELL, $R$. et al. Upper arm anthropometric indicators of nutritional status. Amer. J. clin. Nutr., 29:46-53, 1976.

19. MONTEIRo, C.A. Avaliação do estado nutricional na idade pré-escolar em áreas de baixa renda do Estado de São Paulo. São Paulo, 1982. [Tese de Livre-Docência - Faculdade de Saúde Pública da USP].

20. MONTEIRO, C.A. \& BENfCIO, M.H.D'A. Epidemiologia da desnutrição protéico-calórica. In: Nóbrega, F.J., ed.
Desnutriça intra-uterina o pos-natal. São Paulo, Panamed Editorial, 1981. p. 120-9.

21. MORLEY, D. Nutritional surveillance of young children in developing countries. Int. J. Eipidem., 5:51-5, 1976.

22. PALTI, $H$. et al. Community diagnosis of physical growth of infants based on monitoring in a routine preventive service. J. Epidem. community Hlth, $33: 292-6,1979$.

23. SEOANE, N. \& LATHAM, M.C. Nutritional anthropometry in the identification of malnutrition in childhood. $J$. trop. Pediat., 17:08-103, 1971.

24. SIGULEM, D.M. Contribuição ao estudo da desnutrição energético-protéica em criancas de 6 a 60 meses no Município de São Paulo. Săo Paulo, 1980. [Dissertação de Mestrado - Escola Paulista de Medicina].

25. STANDARD, K.L. et al. Indirect indicators of muscle mass in malnourished infants. Amer. J. clin. Nutr., 7:271-9, 1959.

26. STEEL, R.G.D. \& TORRIE, J.H. Principles and procedures of statistics. New York, McGraw-Hill, 1960.

27. TANNER, J.M. Growth as a monitor of nutritional status. Proc. Nutr. Soc., $35: 315-22,1976$.

28. TANNER, J.M. Population differences in body size, shape and growth rate: a 1976 view. Arch. Dis. Child., 51:1-2, 1976.

29. VAUGHAN, V.C. III. Grosth and develop. ment. In: Vaughan, V.C. III \& Mckay, R.J., ed. Nelson textbook of pediatrics. 10tb ed. Philadelphia, W.B. Saunders, 1975. p. 13-51.

30. WATERLOW, J.C. \& MENDES, C.B. Composition of $\mathrm{m} *$ scle in malnourished human infants. Nature, 180:1.361-2, 1957.

31. WATERLOW, J.C. et al. The presentation and use of height and weight data for comparing the nutritional status of groups of children under the age of 10 years. Bull. Wld Hlth Org., 55:489-98, 1977.

32. YARBROUGH, $C$. et al. Lenght and weight in rural guatemalan ladino children: birth to seven years of age. Amer. $J$. Anthrop., 42:439-48, 1975.

Recebido para publicaşão em 08/06/1983 Aprovado para publicação em 24/10/1983 